\title{
Timing accuracy of PC programs running under DOS and Windows
}

\author{
BRETT MYORS \\ Macquarie University, Sydney, New South Wales, Australia
}

The time in which to press a key and the video retrace interval were measured under various conditions of MS-DOS, Windows 3.1, Windows 3.11, Windows 95, and Windows NT 4.0 Workstation. All the measurements were obtained with the same program running on a single Pentium 300 computer. In all, samples of 1,000 timing measurements were obtained in each of 96 different conditions. Standard deviations of the times ranged from about 0.0006 msec under DOS 6.22 to almost 40 msec under Windows 3.11 , representing an increase in timing error of up to $6,000,000 \%$. Researchers requiring millisecond timing accuracy are recommended to use DOS only.

Several authors have recommended that researchers needing accurate time measurements should avoid multitasking environments such as Windows (Myors, 1998). The purpose of this article is to investigate this claim by comparing video retrace and keypress times under MSDOS and various versions of Windows. This is an important topic for anyone studying reaction times or seeking to precisely control stimuli on a PC, especially given that much modern experimental control software is currently being ported to the Windows environment-for example, DMASTR (Forster \& Forster, 1990).

\section{METHOD}

An MS-DOS program was written in the C programming language to time 1,100 video retrace intervals and keypresses on a Pentium $300-\mathrm{MHz}$ IBM PC-compatible microcomputer. The program was compiled with the Watcom 16-bit C compiler, Version 10.6, using the default compiler options. Keypresses were produced by the typematic feature of the PC keyboard, in which characters are generated when a key is held down for more than about half a second. This ensured a constant stream of characters at a uniform rate. In this case, the space bar was held down for the duration of the timing. Thus, the keypresses are not "presses" as such. The space bar was pressed once at the beginning of the program and the keyboard repeated the "presses" at a constant rate from then on. There is very little uncertainty in this, because it is controlled by the keyboard hardware.

Before timing the keypresses, the program used BIOS interrupt $0 \times 16$ subfunction $0 \times 03$ to reprogram the typematic rate to generate 1 character every half second. This was the slowest possible rate and meant that the computer would not be overburdened by too many keyboard interrupts. The default rate is about 20 characters per second. As such, any timing errors encountered are likely to be due to the computer's being engaged in other tasks than processing of the keyboard.

Correspondence concerning this article should be addressed to B. Myors, School of Behavioural Sciences, Macquarie University, Sydney, New South Wales 2109, Australia (e-mail: bmyors@bunyip.bhs. mq.edu.au).
Next, the program entered the main timing loop and timed the occurrence of 1,100 characters generated by the typematic feature. Timing was carried out using the mode 2 timer (Graves \& Bradley, 1991), which has a period of $838.1 \mathrm{nsec}$ and is the most accurate method of timing events on a PC, short of connecting an external clock. Characters were read with MS-DOS interrupt $0 \times 21$ function $0 \mathrm{x} 0 \mathrm{c}$ subfunction $0 \mathrm{x} 08$. This standard interrupt flushes the keyboard buffer and then reads a character without echo.

The code that collected these data was as follows:

$$
\begin{aligned}
\text { for }(\mathrm{i}=0 & ; \mathrm{i}<1100 ;++\mathrm{i}) \\
& \text { time1( }) ; \\
& \text { intdos(\&inregs, \&outregs); } \\
& \text { time2( }) ; \\
& \mathrm{kb}[\mathrm{i}]=\text { tock; }
\end{aligned}
$$

The time1() function starts the timer and the time2() latches the time into the variable called tock. Because the mode 2 timer was used, the value stored in tock is accurate to the microsecond. Each value of tock was stored in the $k b$ array and later written to a file. The intdos() function is a standard library routine that invokes DOS interrupt $0 \times 21$; it was used to read a character from the keyboard, as described above. The times recorded were those between a fixed start (timel()) and a keypress. Thus, the only uncertainty should have been the duration of the keypress output by the typematic feature. Although the loop was executed 1,100 times, only the middle $\mathrm{I}, 000$ entries in $\mathrm{kb}$ were stored. The first and last few data points were discarded in order to avoid beginning and ending effects, such as the time taken for the experimenter to press the space bar after starting the program.

The program also timed the vertical retrace interval. The code fragment for this is as follows:

$$
\begin{aligned}
& \text { for }(\mathrm{i}=0 ; \mathrm{i}<1100 ;++\mathrm{i}) \\
& \quad \text { SYNC; } \\
& \operatorname{time} 1() ; \\
& \text { for }(\mathrm{j}=0 ; \mathrm{j}<35 ;++\mathrm{j}) \\
& \mathrm{SYNC} ; \\
& \operatorname{time} 2() ; \\
& \operatorname{vid}[\mathrm{i}]=\text { tock; }
\end{aligned}
$$

The SYNC macro synchronizes the loop to the video retrace and is given at the top of the next page. 
\#define VSYNC_STATUS $0 \times 3 \mathrm{da}$

\#define VSYNC_MASK 0x08

\#define SYNC \{while (inp(VSYNC_STATUS) \& VSYNC_MASK); while (!(inp(VSYNC_STATUS) \& VSYNC_MASK));

This is the standard method of locking onto the retrace on a $\mathrm{PC}$.

The two timing loops are very similar. When timing the retrace interval, first the video retrace was found, then the timer was started and an additional 35 retraces counted before the time was latched and stored in the array called vid. Again, only the middle 1,000 entries in vid were written to disk for analysis. Thirty-five retraces were counted in the inner loop, to slow down events and give the computer plenty of time to do the timing. This is analogous to slowing the typematic rate in the case of timing the keyboard. The video card on the computer used in this study refreshed the screen at about $70 \mathrm{~Hz}$, so the duration of the inner loop should be about half a second.

\section{RESULTS}

The main aim of this research was to examine the effect of various configurations of DOS and Windows on the code fragments given above. To this end, the following operating systems were installed and tested in turn: MS-DOS 6.22, Windows 3.1, Windows 3.11, Windows 95, and Windows NT 4.0 Workstation. The same program was run on all occasions. Table 1 shows the mean and standard deviations of the 1,000 entries obtained from each setup. Information about the distributions, in the form of the 5 th, 25th, 50th, 75th, and 95th percentiles, is also provided. Finally, the minimum and maximum times are supplied, to give some idea of the largest error that might be expected in that condition.

\section{DOS 6.22}

The first two rows in Table 1 give the results of the video retrace and keypress times for "raw DOS." Raw DOS was obtained by booting the computer from a floppy disk with no autoexec.bat or config.sys. This is the purest version of DOS operating in real mode. ${ }^{1}$ As can be seen, the timing is very precise. Thirty-five retraces took, on average, $502 \mathrm{msec}$, which is in accordance with a refresh rate of $70 \mathrm{~Hz}$. Similarly, the typematic feature issued a character every $482 \mathrm{msec}$, about as expected. Most importantly, there is very little error in these measurements. The standard deviations indicate that the times varied by only a fraction of a millisecond in each case, and, as can be seen from the percentiles, the distributions of the times are very flat. The range of values (maximum error) was $0.003 \mathrm{msec}$ for timing the retrace and $0.4 \mathrm{msec}$ for timing the keyboard. Clearly, millisecond accuracy in timing the keyboard and controlling the display is possible in raw DOS. This condition serves as the benchmark for judging all the subsequent configurations.

The next two rows in Table 1 show the results of adding a config.sys file, which loaded the himem.sys extended memory manager. As can be seen, the presence of himem.sys had virtually no impact on timing accuracy. Errors were well below $1 \mathrm{msec}$.

The next two rows in Table 1 show the results of adding the emm386.sys expanded memory manager to the above configuration. Emm386.sys places the CPU in virtual 86 mode, which emulates real mode and allows paging of high memory on 80386 CPUs and above. Sargent and Shoemaker $(1995$, p. 252$)$ state that virtual 86 mode can be much slower at handling input/output operations than real mode, but the impact appears to be minimal on the relatively fast computer used in this study. Although there is a very slight increase in keypress times, timing errors are still well below $1 \mathrm{msec}$. This was the only condition in which emm386.sys was loaded.

\section{Windows 3.1 in Standard Mode}

Standard mode was available in Windows 3.0 and 3.1 and was designed for 80286 CPUs. In standard mode, DOS programs run in real mode. Although they can be switched, they cannot be multitasked or run in a window. The availability of switching is an option that can be controlled by the user via a check box in the PIF editor used to create the program's program information file (PIF). In this and all subsequent Windows conditions, the only application program running was the timing program, and it always ran in the foreground.

Windows 3.1 documentation states that many programs run faster in standard mode than in enhanced mode (Microsoft, 1992, p. 13), and the results in Table 1 show that standard mode produces timing accuracies that are virtually the same as those for DOS. Table 1 shows results for standard mode when task switching is and is not allowed. Standard mode seems quite acceptable for running experimental tasks. Unfortunately, standard mode became unavailable with the release of Windows 3.11.

\section{Windows 3.1 in Enhanced Mode}

Windows 3.1 running in enhanced mode runs DOS programs in protected mode. This allows multitasking of DOS and Windows sessions, as well as allowing DOS programs to run in a window. In addition, multitasking options (exclusive and background) can be set in the PIF or via the DOS box control menu. Explanations of these options can be found in the PIF Editor help file. Briefly, when exclusive is checked, the program has exclusive use of system resources-that is, nothing else runs in the background. When background is checked, the program may run in the background when it is not active. Another variable that was considered was whether the program was running full screen or in a window. Programs running full screen usually run faster, because their output does not need to be translated into graphics.

As is shown in Table 1, timing accuracy collapses dramatically in enhanced mode. The first thing to notice is that the video retrace is not being detected correctly when the program is running in a window. The mean of the 35 retraces in these conditions is about $28 \mathrm{msec}$, rather than being about $483 \mathrm{msec}$. The remaining results for these conditions should be ignored.

When the program was running full screen, the standard deviations were about $37 \mathrm{msec}$, in contrast to the $0.0006 \mathrm{msec}$ found for DOS. This is an increase in inaccuracy of over $6,000,000 \%$. Furthermore, a constant of 
about $30 \mathrm{msec}$ seems to have been added to the retrace times. In DOS, retrace times were averaging about $501 \mathrm{msec}$; in these conditions, they are averaging about $530 \mathrm{msec}$. Frequency distributions of the four full-screen conditions show trimodal distributions with a large central peak and two smaller peaks in either tail.

Results for the keypresses are fairly similar. All the conditions had sensible means, although, again, there was an almost 30-msec increase in average times. Standard deviations were around $28 \mathrm{msec}$, as compared with about $0.065 \mathrm{msec}$ for DOS - an increase in inaccuracy of over $40,000 \%$. There were two distinct patterns in the frequency distributions of the keypresses. When obtained through running in a window, all the distributions looked bell shaped, but the distributions in the full-screen conditions looked like a step--a range of shorter intervals at a fairly constant frequency, followed by a range of longer intervals at a fairly constant higher frequency.

\section{Windows 3.11}

Windows 3.11 only runs in enhanced mode and has the same multitasking options as those found in Windows 3.1. Nevertheless, it was a significant upgrade and had many enhancements. As in the previous section, eight conditions were examined: all combinations of the multitasking options running full screen and in a window. The results are shown in Table 1 and are very similar to those obtained for Windows 3.1 in enhanced mode. As before, the program was unable to detect the vertical retrace when running in a window (means of about $28 \mathrm{msec}$ ), and there was an increase of about $30 \mathrm{msec}$ on all the other average times. The degree of timing inaccuracy was also similar. In general, the frequency distributions of the video retrace intervals and the keypresses were also similar to those found for Windows 3.1 in enhanced mode. Clearly, Windows $3 . x$ is not suitable for running experiments in which the precise control of stimuli or the precise measurement of responses is required.

\section{Windows 95}

Windows 95 offered a more integrated operating system, with less dependency on DOS. The first three conditions examined were various ways of restarting Windows 95 in DOS mode. In all cases, the DOS version reported was 4.00.1111. The simplest method is to select "Restart in DOS mode" from the "Shut down" menu. As is shown in Table 1, the results for this condition are almost identical to those found for DOS, reported above.

The next method examined was pressing F8 during the Windows 95 startup and selecting "Command prompt only." Again, the results were very similar to those found for DOS. Although there is a noticeable increase in error in timing the video retrace, it is still well under a millisecond.

The third technique for accessing DOS was to get Windows to create a temporary autoexec.bat and config.sys file before shutting down and running the DOS program. This is done by checking the "MS-DOS mode" box in the "Advanced Program Settings" dialog found under the "Program" tab of the "Properties" menu. As is shown in Table 1, the results are very similar to those found previously, indicating that, when running in DOS mode, the Windows 95 version of DOS is adequate for precise experimentation.

When running a DOS box in the main Windows 95 multitasking environment, however, timing accuracy is not nearly as good. Windows 95 has a set of multitasking options similar to those found in Windows 3.x: always suspend and idle sensitivity. These can be accessed under the "Misc" tab of the "Properties" menu associated with the program If checked, always suspend prevents the program from running in the background (i.e., it is always suspended). Idle sensitivity is controlled by a slider rather than a check box and determines the degree of multitasking that occurs with the program. If idle sensitivity is low, not much task switching takes place; if idle sensitivity is high, a lot of task switching occurs. For the purposes of this study, the idle sensitivity slider was set at either its minimum or its maximum position. Four combinations of these settings gives rise to eight conditions when run in full screen or a window.

Table 1 shows the results. As with Windows 3.x, the program was unable to detect the video retrace when running in a window (means of $28 \mathrm{msec}$ ). Averages of the remaining conditions were similar to those obtained for Windows 3.x: 35 video retraces were estimated to occur in about $529 \mathrm{msec}$ (about $30 \mathrm{msec}$ longer than in DOS), and keypresses were timed to take about $511 \mathrm{msec}$ (also about $30 \mathrm{msec}$ longer than their DOS equivalents). However, the standard deviations of the times were half of what they were for Windows $3 . x$, about $16 \mathrm{msec}$. Although this is an improvement, it is still inadequate for achieving millisecond accuracy. Unlike the distributions found in Windows 3.x, all the frequency distributions obtained under Windows 95 were very rectangular, with no obvious mode, indicating a fairly even dispersion of values for both the video retrace and the keypress times.

\section{Windows NT 4.0 Workstation}

Windows NT offers a significant departure from the previous versions of Windows and may represent the future of this family of operating systems. It includes enhanced security features and enforces application programs to reside in their own memory space. Violations of system integrity are rarer than with the other versions of Windows. The DOS version reported was Windows NT 4.00 .

Although it does not have the option of "restarting in DOS mode," Windows NT offers an additional checkbox in the "Windows NT" dialog of the "Program" tab of the "Properties" menu labeled "Compatible Timer Hardware Emulation." When checked, this option allows the system to emulate the hardware timer; when not checked, the actual hardware timer is used. This extra dichotomy led to 16 possible conditions under Windows NT. The first 8 conditions examined were obtained when the hardware timer emulation was disabled. 
The results are shown in Table 1. The first thing to notice about these data is that the keyboard is not being processed correctly (mean keypress time is $58 \mathrm{msec}$, rather than about half a second). Even the maximums are well under what they should be, averaging about $140 \mathrm{msec}$. Similarly, when idle sensitivity is high, the video retrace is not being processed correctly (mean of $1,057 \mathrm{msec}$, rather than about half a second). In this case, the minimums are way too high (about $922 \mathrm{msec}$ ). The reason for these effects is unclear.

The only conditions in which the means are sensible are those for the video retrace with low idle sensitivity. These conditions had a mean of about $512 \mathrm{msec}$ and a standard deviation of about $26 \mathrm{msec}$. Looking at the distributions, the times were concentrated in about four values, but clearly the error is still far too high.

The second set of results for Windows NT was obtained when the hardware timer was enabled. These are shown in Table 1. Interestingly, they are very similar to the previous set, indicating that hardware timer emulation does not have much impact on the processes examined here. The keyboard is still not being monitored correctly (mean time equals $58 \mathrm{msec}$, with a maximum of about $136 \mathrm{msec}$, rather than half a second); and, as before, the video retrace is not working when idle sensitivity is high (mean time equals $1,064 \mathrm{msec}$, with a minimum of about $922 \mathrm{msec}$, rather than half a second). This leaves the video retrace under conditions of low idle sensitivity as the only conditions whose mean performance is sensible (mean of $512 \mathrm{msec}$ ). Unfortunately, the error involved in these conditions is still unacceptably large (standard deviation of about $27 \mathrm{msec}$ ). Again, the times in these four distributions are concentrated into about four different values.

\section{CONCLUSION}

This article chronicles the imprecision in experimental control afforded by the Windows environment. Although there has been some improvement with subsequent releases, no version of Windows provides the minimum standard of timing accuracy required by experimental psychology. The most likely source of the problem is protected mode. Running under Windows in protected mode, application programs run in ring three, the lowest priority level of execution. In contrast, the spirit of MS-DOS was to give application programs total control of the computer's hardware (Sargent \& Shoemaker, 1995, p. 256). This is the ultimate level of privileged execution. Programs need to run in ring zero in protected mode to get this level of priority, and the only way to do that under Windows is to run as a virtual device driver ( $\mathrm{VxD}$; Sargent \& Shoemaker, 1995). However, it is not feasible to write an entire experimental control program, including the timing and stimulus/response control, as a VxD. In any case, there is no guarantee that the Windows kernel will not interfere and produce further errors when the program is being multitasked.

Total control of the hardware is extremely desirable from a research point of view when the $\mathrm{PC}$ is used as a scientific instrument. This is not the spirit of Windows, which seeks to achieve device independence and provide a generic, user-friendly multitasking environment. The tradeoff between usability and precision is evident in the data reported here. Warnings by past writers about multitasking environments appear to be justified.

Of course, accuracy of means can always be increased by using a large number of observations, as was the case here, but many experimenters will not be in a position to collect thousands of observations per condition. Therefore, researchers interested in the precise measurement of time, whether it is the reaction time of a response or the precise control of stimuli, are strongly urged not to run their experiments under Windows.

It could be argued that these results only apply to DOS programs running in a Windows DOS box; however, given that DOS is preemptively multitasked in all versions of Windows, it is likely that the problems illustrated here are due to the multitasking kernel per se and will be evident in programs written specifically for Windows. Given the extensiveness of the problems uncovered in this article, it is a fairly safe prediction that forthcoming versions of Windows (Windows 98 and NT 5.0) will suffer similar deficiencies from a research point of view. Until better methods are established, it is safer for experimenters to stay with DOS.

\section{REFERENCES}

FORSTER, K. I., \& FORSTER, J. C. (1990). DMASTR control system: Laboratory software for mental chronometry. Unpublished manuscript. Graves, R. E., \& Bradley, R. (1991). Millisecond timing on the IBM $\mathrm{PC} / \mathrm{XT} / \mathrm{AT}$ and PS/2: A review of the options and corrections for the Graves and Bradley algorithm. Behavior Research Methods, Instruments, \& Computers, 23, 377-379.

MicrosofT (1992). Getting started with Microsoft Windows. Washington, DC: Microsoft Corporation.

MYORS, B. (1998). A simple graphical technique for assessing timer accuracy of computer systems. Behavior Research Methods, Instruments, \& Computers, 30, 454-456.

SARGENT, M., III, \& ShOEMAKER, R. L. (1995). The personal computer from the inside out (3rd ed.). New York: Addison-Wesley.

\section{NOTE}

1. Real mode was the native operating mode of original $8086 \mathrm{CPU}$ and has a maximum address space of one megabyte. All $\times 86$ chips can operate in real mode, but, starting with the 80286 , the preferred mode was protected mode. Protected mode was designed to enable multitasking and has an address space of many megabytes. The "Enhanced Mode" of Windows $3 . x$ and subsequent versions operate in protected mode. Because of its simplicity, real mode is usually faster. 
Table 1

Means, Standard Deviations, and Frequency Distributions (in Milliseconds) of Video Retrace Intervals and Keypresses for Various Conditions of DOS and Windows

\begin{tabular}{|c|c|c|c|c|c|c|c|c|c|}
\hline Condition & Mean & $S D$ & Minimum & $\begin{array}{c}\text { 5th } \\
\text { Percentile }\end{array}$ & $\begin{array}{c}25 \text { th } \\
\text { Percentile }\end{array}$ & $\begin{array}{c}50 \text { th } \\
\text { Percentile }\end{array}$ & $\begin{array}{c}\text { 75th } \\
\text { Percentile }\end{array}$ & $\begin{array}{c}\text { 95th } \\
\text { Percentile }\end{array}$ & Maximum \\
\hline \multicolumn{10}{|l|}{ DOS } \\
\hline $\begin{array}{l}\text { Video retrace in raw DOS booted } \\
\text { from floppy without autoexec.bat } \\
\text { or config.sys }\end{array}$ & 501.7 & 0.0006 & $6 \quad 501.7$ & 501.7 & 501.7 & 501.7 & 501.7 & 501.7 & 501.7 \\
\hline Keypress in above condition & 482.2 & 0.0648 & $8 \quad 482.0$ & 482.1 & 482.1 & 482.2 & 482.2 & 482.3 & 482.4 \\
\hline $\begin{array}{l}\text { Video retrace in DOS when } \\
\text { himem.sys is loaded }\end{array}$ & 501.7 & 0.0005 & 5501.7 & 501.7 & 501.7 & 501.7 & 501.7 & 501.7 & 501.7 \\
\hline Keypress in above condition & 483.0 & 0.0688 & 8482.9 & 482.9 & 483.0 & 483.0 & 483.1 & 483.2 & 483.3 \\
\hline $\begin{array}{l}\text { Video retrace when himem.sys and } \\
\text { emm386.sys are loaded }\end{array}$ & 501.7 & 0.0006 & $6 \quad 501.7$ & 501.7 & 501.7 & 501.7 & 501.7 & 501.7 & 501.7 \\
\hline Keypress in above condition & 484.4 & 0.0658 & 8484.3 & 484.3 & 484.4 & 484.4 & 484.4 & 484.5 & 484.6 \\
\hline \multicolumn{10}{|l|}{ Windows 3.1 in Standard Mode } \\
\hline $\begin{array}{l}\text { 4.0 Video retrace, prevent program } \\
\text { switch not checked }\end{array}$ & 501.7 & 0.0005 & $5 \quad 501.7$ & 501.7 & 501.7 & 501.7 & 501.7 & 501.7 & 501.7 \\
\hline Keypress in above condition & 484.6 & 0.0592 & 2484.4 & 484.5 & 484.5 & 484.5 & 484.6 & 484.7 & 484.8 \\
\hline $\begin{array}{l}\text { Video retrace, prevent program } \\
\text { switch checked }\end{array}$ & 501.7 & 0.0005 & $5 \quad 501.7$ & 501.7 & 501.7 & 501.7 & 501.7 & 501.7 & 501.7 \\
\hline Keypress in above condition & 484.7 & 0.0636 & 6484.6 & 484.6 & 484.7 & 484.7 & 484.7 & 484.9 & 484.9 \\
\hline \multicolumn{10}{|l|}{ Windows 3.1 in Enhanced Mode } \\
\hline $\begin{array}{l}\text { Video retrace running full screen } \\
\text { with exclusive not checked and } \\
\text { background not checked }\end{array}$ & 529.2 & 37.3 & 442.7 & 463.7 & 502.5 & 527.5 & 549.2 & 594.9 & 619.3 \\
\hline Keypress in above condition & 512.5 & 29.0 & 408.3 & 451.6 & 499.4 & 516.8 & 534.0 & 547.6 & 603.4 \\
\hline $\begin{array}{l}\text { Video retrace running in a window } \\
\text { with exclusive not checked and } \\
\text { background not checked }\end{array}$ & 28.0 & 16.3 & 0.0 & 2.6 & 14.2 & 28.0 & 41.3 & 52.3 & 109.8 \\
\hline Keypress in above condition & 512.7 & 24.4 & 439.5 & 477.5 & 497.8 & 511.6 & 525.6 & 547.5 & 598.9 \\
\hline $\begin{array}{l}\text { Video retrace running full screen } \\
\text { with exclusive checked and } \\
\text { background not checked }\end{array}$ & 528.9 & 36.0 & 453.1 & 469.7 & 503.2 & 523.9 & 549.0 & 591.0 & 643.6 \\
\hline Keypress in above condition & 511.7 & 29.2 & 427.3 & 451.1 & 498.0 & 516.3 & 533.6 & 547.1 & 600.5 \\
\hline $\begin{array}{l}\text { Video retrace running in a window } \\
\text { with exclusive checked and } \\
\text { background not checked }\end{array}$ & 28.1 & 16.5 & 0.0 & 2.9 & 14.5 & 27.8 & 41.2 & 52.2 & 107.9 \\
\hline Keypress in above condition & 512.8 & 24.9 & 439.4 & 479.0 & 498.8 & 512.9 & 526.5 & 547.2 & 602.2 \\
\hline $\begin{array}{l}\text { Video retrace running full screen } \\
\text { with exclusive not checked and } \\
\text { background checked }\end{array}$ & 529.4 & 36.5 & 449.3 & 468.6 & 503.6 & 525.9 & 550.5 & 591.7 & 646.6 \\
\hline Keypress in above condition & 512.0 & 28.8 & 432.1 & 451.4 & 498.3 & 515.7 & 533.2 & 547.1 & 597.9 \\
\hline $\begin{array}{l}\text { Video retrace running in a window } \\
\text { with exclusive not checked and } \\
\text { background checked }\end{array}$ & 27.8 & 16.4 & 0.1 & 2.6 & 13.5 & 28.1 & 41.7 & 52.5 & 101.1 \\
\hline Keypress in above condition & 511.1 & 28.7 & 439.9 & 460.7 & 495.1 & 511.9 & 527.3 & 548.4 & 603.8 \\
\hline $\begin{array}{l}\text { Video retrace running full screen } \\
\text { with exclusive checked and } \\
\text { background checked }\end{array}$ & 529.2 & 37.3 & 440.9 & 466.6 & 503.3 & 527.2 & 551.9 & 593.0 & 612.9 \\
\hline Keypress in above condition & 510.8 & 29.9 & 395.7 & 449.4 & 497.0 & 515.0 & 533.1 & 547.0 & 601.2 \\
\hline $\begin{array}{l}\text { Video retrace running in a window } \\
\text { with exclusive checked and } \\
\text { background checked }\end{array}$ & 27.9 & 16.4 & 0.1 & 2.7 & 13.5 & 28.1 & 41.8 & 52.5 & 104.0 \\
\hline Keypress in above condition & 510.7 & 32.6 & 439.4 & 447.1 & 494.4 & 514.7 & 530.5 & 549.0 & 604.1 \\
\hline \multicolumn{10}{|l|}{ Windows 3.11} \\
\hline $\begin{array}{l}\text { Video retrace running full screen } \\
\text { with exclusive not checked and } \\
\text { background not checked }\end{array}$ & 528.9 & 37.6 & 397.0 & 466.2 & 503.0 & 525.4 & 551.2 & 591.9 & 654.1 \\
\hline Keypress in above condition & 510.8 & 28.7 & 412.9 & 452.4 & 497.1 & 514.6 & 533.0 & 546.2 & 597.9 \\
\hline $\begin{array}{l}\text { Video retrace running in a window } \\
\text { with exclusive not checked and } \\
\text { background not checked }\end{array}$ & 27.7 & 16.6 & 0.0 & 2.8 & 13.5 & 27.2 & 41.5 & 52.5 & 104.7 \\
\hline Keypress in above condition & 511.8 & 27.7 & 439.4 & 447.4 & 498.8 & 514.5 & 529.2 & 546.4 & 604.0 \\
\hline $\begin{array}{l}\text { Video retrace running full screen } \\
\text { with exclusive checked and } \\
\text { background not checked }\end{array}$ & 529.2 & 35.1 & 454.9 & 471.7 & 503.6 & 522.7 & 548.9 & 592.0 & 603.9 \\
\hline Keypress in above condition & 510.9 & 29.3 & 390.8 & 449.9 & 498.2 & 516.1 & 533.4 & 546.9 & 600.8 \\
\hline Video retrace running in a window & 27.6 & 16.3 & 0.0 & 2.6 & 13.3 & 27.9 & 41.4 & 52.3 & 109.4 \\
\hline
\end{tabular}


Table 1 (Continued)

\begin{tabular}{|c|c|c|c|c|c|c|c|c|c|}
\hline Condition & Mean & $S D$ & Minimum & $\begin{array}{c}\text { 5th } \\
\text { Percentile }\end{array}$ & $\begin{array}{c}\text { 25th } \\
\text { Percentile }\end{array}$ & $\begin{array}{c}\text { 50th } \\
\text { Percentile }\end{array}$ & $\begin{array}{c}\text { 75th } \\
\text { Percentile } \\
\end{array}$ & $\begin{array}{c}\text { 95th } \\
\text { Percentile }\end{array}$ & Maximum \\
\hline \multicolumn{10}{|l|}{$\begin{array}{l}\text { with exclusive checked and } \\
\text { background not checked }\end{array}$} \\
\hline Keypress in above condition & 511.7 & 27.4 & 439.4 & 447.2 & 498.3 & 513.7 & 528.1 & 546.3 & 603.4 \\
\hline $\begin{array}{l}\text { Video retrace running full screen } \\
\text { with exclusive not checked and } \\
\text { backgground checked }\end{array}$ & 529.5 & 36.7 & 442.3 & 463.7 & 503.0 & 528.2 & 548.8 & 594.5 & 635.5 \\
\hline Keypress in above condition & 510.7 & 29.7 & 408.3 & 450.0 & 497.5 & 515.6 & 532.9 & 546.8 & 601.2 \\
\hline $\begin{array}{l}\text { Video retrace running in a window } \\
\text { with exclusive not checked and } \\
\text { background checked }\end{array}$ & 27.6 & 16.6 & 0.0 & 2.7 & 13.4 & 26.9 & 41.3 & 52.5 & 108.6 \\
\hline Keypress in above condition & 511.2 & 20.9 & 440.2 & 478.3 & 497.3 & 511.0 & 524.7 & 546.3 & 594.7 \\
\hline $\begin{array}{l}\text { Video retrace running full screen } \\
\text { with exclusive checked and } \\
\text { background checked }\end{array}$ & 529.0 & 38.5 & 400.2 & 460.2 & 503.4 & 529.5 & 554.1 & 591.2 & 606.3 \\
\hline Keypress in above condition & 510.6 & 31.4 & 386.3 & 445.4 & 498.3 & 515.9 & 533.8 & 547.0 & 595.7 \\
\hline $\begin{array}{l}\text { Video retrace running in a window } \\
\text { with exclusive checked and } \\
\text { background checked }\end{array}$ & 27.6 & 16.7 & 0.2 & 2.7 & 13.2 & 27.5 & 41.7 & 52.5 & 106.4 \\
\hline Keypress in above condition & 511.1 & 37.5 & 439.6 & 448.1 & 483.0 & 510.7 & 529.8 & 591.9 & 603.9 \\
\hline \multicolumn{10}{|l|}{ Windows 95} \\
\hline Video retrace restarted in DOS mode & 501.7 & 0.0006 & $5 \quad 501.7$ & 501.7 & 501.7 & 501.7 & 501.7 & 501.7 & 501.7 \\
\hline Keypress in above condition & 483.5 & 0.0659 & 483.3 & 483.4 & 483.4 & 483.5 & 483.5 & 483.6 & 483.7 \\
\hline $\begin{array}{l}\text { Video retrace F8 pressed on } \\
\text { start up and started as } \\
\text { "Command Prompt only" }\end{array}$ & 501.7 & 0.0029 & 501.7 & 501.7 & 501.7 & 501.7 & 501.7 & 501.7 & 501.7 \\
\hline Keypress in above condition & 482.0 & 0.0641 & 481.8 & 481.9 & 481.9 & 482.0 & 482.0 & 482.1 & 482.2 \\
\hline $\begin{array}{l}\text { Video retrace started in MS-DOS mode } \\
\text { with system shutting down and } \\
\text { restarting having written } \\
\text { temporary autoexec.bat and } \\
\text { config.sys files. }\end{array}$ & 501.7 & 0.0006 & 501.7 & 501.7 & 501.7 & 501.7 & 501.7 & 501.7 & 501.7 \\
\hline Keypress in above condition & 481.9 & 0.0953 & 481.7 & 481.8 & 481.8 & 481.9 & 481.9 & 482.1 & 482.2 \\
\hline $\begin{array}{l}\text { Video retrace running full screen, } \\
\text { always suspend not checked, } \\
\text { idle sensitivity low }\end{array}$ & 529.5 & 16.0 & 501.7 & 504.6 & 515.8 & 529.6 & 543.0 & 554.1 & 566.2 \\
\hline Keypress in above condition & 509.4 & 15.9 & 482.0 & 484.6 & 495.7 & 509.5 & 523.1 & 534.1 & 537.0 \\
\hline $\begin{array}{l}\text { Video retrace running in a window, } \\
\text { always suspend not checked, } \\
\text { idle sensitivity low }\end{array}$ & 28.3 & 15.8 & 1.0 & 3.7 & 14.7 & 28.5 & 42.8 & 52.5 & 55.9 \\
\hline Keypress in above condition & 511.0 & 15.9 & 483.3 & 486.6 & 497.3 & 511.0 & 524.7 & 535.6 & 538.8 \\
\hline $\begin{array}{l}\text { Video retrace running full screen, } \\
\text { always suspend checked, } \\
\text { idle sensitivity low }\end{array}$ & 529.5 & 16.0 & 501.8 & 504.3 & 515.5 & 529.8 & 543.4 & 554.4 & 568.6 \\
\hline Keypress in above condition & 510.3 & 15.9 & 482.9 & 485.6 & 496.5 & 510.2 & 524.0 & 534.9 & 537.8 \\
\hline $\begin{array}{l}\text { Video retrace running in a window, } \\
\text { always suspend checked, } \\
\text { idle sensitivity low }\end{array}$ & 28.4 & 15.9 & 1.0 & 3.6 & 15.0 & 28.7 & 42.5 & 52.8 & 55.8 \\
\hline Keypress in above condition & 511.0 & 15.9 & 483.3 & 486.2 & 497.2 & 510.9 & 524.6 & 535.7 & 538.8 \\
\hline $\begin{array}{l}\text { Video retrace running full screen, } \\
\text { always suspend not checked, } \\
\text { idle sensitivity high }\end{array}$ & 529.2 & 15.9 & 501.7 & 504.6 & 515.9 & 528.9 & 542.7 & 553.8 & 567.2 \\
\hline Keypress in above condition & 509.6 & 15.9 & 482.3 & 484.8 & 495.8 & 509.5 & 523.3 & 534.3 & 537.1 \\
\hline $\begin{array}{l}\text { Video retrace running in a window, } \\
\text { always suspend not checked, } \\
\text { idle sensitivity high }\end{array}$ & 28.2 & 15.7 & 1.1 & 4.2 & 14.6 & 28.3 & 42.1 & 52.5 & 56.0 \\
\hline Keypress in above condition & 512.0 & 15.9 & 484.3 & 487.4 & 498.3 & 512.1 & 525.8 & 536.7 & 539.7 \\
\hline $\begin{array}{l}\text { Video retrace running full screen, } \\
\text { always suspend checked, } \\
\text { idle sensitivity high }\end{array}$ & 529.5 & 16.0 & 501.8 & 504.6 & 515.7 & 529.5 & 543.2 & 554.2 & 568.6 \\
\hline Keypress in above condition & 511.3 & 15.9 & 483.8 & 486.6 & 497.6 & 511.3 & 525.1 & 536.1 & 538.8 \\
\hline $\begin{array}{l}\text { Video retrace running in a window, } \\
\text { always suspend checked, } \\
\text { idle sensitivity high }\end{array}$ & 28.1 & 15.7 & 0.0 & 3.9 & 13.7 & 28.3 & 42.1 & 52.5 & 55.9 \\
\hline Keypress in above condition & 512.0 & 15.8 & 484.4 & 487.1 & 498.1 & 511.9 & 525.8 & 536.8 & 539.7 \\
\hline \multicolumn{10}{|c|}{ Windows NT 4.0 Workstation with no hardware timer emulation } \\
\hline $\begin{array}{l}\text { Video retrace running full screen, } \\
\text { always suspend not checked, }\end{array}$ & 514.9 & 26.4 & 473.5 & 474.6 & 474.6 & 529.6 & 529.6 & 543.5 & 543.8 \\
\hline
\end{tabular}


Table 1 (Continued)

\begin{tabular}{|c|c|c|c|c|c|c|c|c|c|}
\hline Condition & Mean & $S D$ & Minimum & $\begin{array}{c}\text { 5th } \\
\text { Percentile } \\
\end{array}$ & $\begin{array}{c}\text { 25th } \\
\text { Percentile }\end{array}$ & $\begin{array}{c}50 \text { th } \\
\text { Percentile }\end{array}$ & $\begin{array}{c}\text { 75th } \\
\text { Percentile }\end{array}$ & $\begin{array}{c}\text { 95th } \\
\text { Percentile }\end{array}$ & Maximum \\
\hline idle sensitivity low & & & & & & & & & \\
\hline Keypress in above condition & 63.9 & 35.0 & 9.4 & 9.8 & 32.7 & 83.8 & 87.7 & 121.5 & 162.3 \\
\hline $\begin{array}{l}\text { Video retrace running in a window, } \\
\text { always suspend not checked, } \\
\text { idle sensitivity low }\end{array}$ & 510.1 & 26.3 & 474.6 & 474.6 & 474.6 & 529.6 & 529.6 & 530.0 & 530.1 \\
\hline Keypress in above condition & 63.8 & 34.4 & 9.8 & 13.8 & 32.7 & 85.6 & 87.7 & 112.8 & 164.4 \\
\hline $\begin{array}{l}\text { Video retrace running full screen, } \\
\text { always suspend checked, } \\
\text { idle sensitivity low }\end{array}$ & 513.4 & 26.8 & 473.8 & 474.6 & 474.6 & 529.6 & 529.6 & 543.5 & 543.9 \\
\hline Keypress in above condition & 63.8 & 35.0 & 9.3 & 9.8 & 32.7 & 84.0 & 87.7 & 121.6 & 152.7 \\
\hline $\begin{array}{l}\text { Video retrace running in a window, } \\
\text { always suspend checked, } \\
\text { idle sensitivity low }\end{array}$ & 509.9 & 26.3 & 474.6 & 474.6 & 474.6 & 529.6 & 529.6 & 530.0 & 530.1 \\
\hline Keypress in above condition & 63.7 & 34.7 & 9.8 & 13.7 & 32.7 & 85.6 & 87.7 & 113.6 & 164.4 \\
\hline $\begin{array}{l}\text { Video retrace running full screen, } \\
\text { always suspend not checked, } \\
\text { idle sensitivity high }\end{array}$ & $1,056.7$ & 55.7 & 921.8 & 921.8 & $1,032.6$ & $1,096.2$ & $1,096.3$ & $1,096.3$ & $1,275.8$ \\
\hline Keypress in above condition & 52.0 & 37.3 & 0.3 & 1.1 & 5.3 & 61.1 & 86.2 & 106.0 & 153.5 \\
\hline $\begin{array}{l}\text { Video retrace running in a window, } \\
\text { always suspend not checked, } \\
\text { idle sensitivity high }\end{array}$ & $1,056.5$ & 55.1 & 921.8 & 921.8 & $1,032.6$ & $1,096.2$ & $1,096.3$ & $1,096.3$ & $1,096.4$ \\
\hline Keypress in above condition & 53.7 & 39.0 & 0.5 & 1.2 & 5.8 & 61.3 & 87.7 & 107.0 & 109.8 \\
\hline $\begin{array}{l}\text { Video retrace running full screen, } \\
\text { always suspend checked, } \\
\text { idle sensitivity high }\end{array}$ & $1,056.5$ & 55.5 & 921.8 & 921.8 & $1,032.6$ & $1,096.2$ & $1,096.3$ & $1,096.3$ & $1,096.3$ \\
\hline Keypress in above condition & 51.4 & 37.3 & 0.4 & 1.2 & 4.8 & 61.1 & 86.1 & 105.2 & 109.8 \\
\hline $\begin{array}{l}\text { Video retrace running in a window, } \\
\text { always suspend checked, } \\
\text { idle sensitivity high }\end{array}$ & $1,056.3$ & 55.7 & 921.8 & 921.8 & $1,032.6$ & $1,096.2$ & $1,096.3$ & $1,096.3$ & $1,165.0$ \\
\hline Keypress in above condition & 53.7 & 38.9 & 0.3 & 1.1 & 5.6 & 61.4 & 87.8 & 106.9 & 109.7 \\
\hline \multicolumn{10}{|c|}{ Windows NT 4.0 Workstation with hardware timer emulation } \\
\hline $\begin{array}{l}\text { Video retrace running full screen, } \\
\text { always suspend not checked, } \\
\text { idle sensitivity low }\end{array}$ & 513.5 & 26.9 & 473.7 & 474.6 & 474.6 & 529.6 & 529.6 & 543.5 & 543.9 \\
\hline Keypress in above condition & 62.7 & 37.2 & 9.7 & 9.8 & 32.8 & 64.8 & 87.8 & 134.5 & 152.3 \\
\hline $\begin{array}{l}\text { Video retrace running in a window, } \\
\text { always suspend not checked, } \\
\text { idle sensitivity low }\end{array}$ & 510.2 & 26.2 & 474.6 & 474.6 & 474.6 & 529.6 & 529.6 & 529.7 & 530.1 \\
\hline Keypress in above condition & 63.3 & 36.2 & 9.8 & 11.4 & 32.8 & 83.5 & 87.8 & 133.8 & 164.4 \\
\hline $\begin{array}{l}\text { Video retrace running full screen, } \\
\text { always suspend checked, } \\
\text { idle sensitivity low }\end{array}$ & 513.2 & 26.7 & 473.6 & 474.6 & 474.6 & 529.6 & 529.6 & 543.5 & 543.9 \\
\hline Keypress in above condition & 63.2 & 37.5 & 9.6 & 9.8 & 32.8 & 83.8 & 87.8 & 124.4 & 151.9 \\
\hline $\begin{array}{l}\text { Video retrace running in a window, } \\
\text { always suspend checked, } \\
\text { idle sensitivity low }\end{array}$ & 510.2 & 26.3 & 474.2 & 474.6 & 474.6 & 529.6 & 529.6 & 529.7 & 530.1 \\
\hline Keypress in above condition & 63.5 & 36.7 & 9.8 & 11.7 & 32.9 & 83.7 & 87.8 & 135.3 & 163.8 \\
\hline $\begin{array}{l}\text { Video retrace running full screen, } \\
\text { always suspend checked, } \\
\text { idle sensitivity high }\end{array}$ & $1,064.0$ & 55.1 & 921.8 & 921.8 & $1,032.6$ & $1,096.2$ & $1,096.3$ & $1,151.2$ & $1,165.0$ \\
\hline Keypress in above condition & 51.3 & 37.1 & 0.3 & 1.1 & 4.8 & 61.1 & 86.1 & 106.0 & 115.0 \\
\hline $\begin{array}{l}\text { Video retrace running in a window, } \\
\text { always suspend checked, } \\
\text { idle sensitivity high }\end{array}$ & $1,063.7$ & 53.2 & 921.8 & 976.7 & $1,032.6$ & $1,096.2$ & $1,096.3$ & $1,151.2$ & $1,220.0$ \\
\hline Keypress in above condition & 54.2 & 39.2 & 0.4 & 1.1 & 5.9 & 61.7 & 87.8 & 107.4 & 120.8 \\
\hline $\begin{array}{l}\text { Video retrace running full screen, } \\
\text { always suspend not checked, } \\
\text { idle sensitivity high }\end{array}$ & $1,063.6$ & 53.9 & 921.8 & 921.9 & $1,032.6$ & $1,096.2$ & $1,096.3$ & $1,151.2$ & $1,151.2$ \\
\hline Keypress in above condition & 51.6 & 37.0 & 0.3 & 1.1 & 5.1 & 61.0 & 86.1 & 106.0 & 109.8 \\
\hline $\begin{array}{l}\text { Video retrace running in a window, } \\
\text { always suspend not checked, } \\
\text { idle sensitivity high }\end{array}$ & $1,064.2$ & 53.8 & 921.7 & 921.9 & $1,032.6$ & $1,096.2$ & $1,096.3$ & $1,151.2$ & $1,151.3$ \\
\hline Keypress in above condition & 54.3 & 39.4 & 0.4 & 1.2 & 5.5 & 62.1 & 87.8 & 107.2 & 109.8 \\
\hline
\end{tabular}

